\section{RECENT LOW-TEMPERATURE RESEARCH AT THE IMPERIAL COLLEGE OF SCIENCE AND 18 TECHNOLOGY}

\footnotetext{
$\mathrm{T}$
}

HE fourth meeting of the Low Temperature Group of the Phyfical Society was held on May 15 in the Departipont of Chemical Engineering and Applied fherfigry, Imperial College, when the work of the Spartmont in the field of low-temperature techndlogy was described and the laboratories and"oqfipment were open to inspection by members

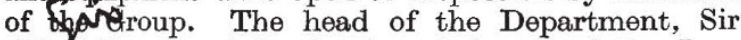
Alfrod Egerton (who is also chairman of the Low Temperature Group), describing the origin of his interest in low-temperature technology, said that in a country where petrol is not indigenous, as much use as possible should be made of the hydrocarbon methane, which can be made available in unlimited quantities from coal. One use that is feasible is as a fuel for internal combustion engines. The best way to carry methane on motor-vehicles is as a liquid in vacuum-jacketed tanks, at approximately atmospheric pressure and normal boiling point, $-161 \cdot 4^{\circ} \mathrm{C}$.

During the War a variety of problems connected with this subject were attacked and solved, to the point where it would have been possible, if required, to produce cheap liquid methane on a large scale and to provide motor-vehicles with reliable equipment which would permit the use of either petrol or liquid methane, according to which was available. The cost of liquid methane from coal gases would not be so low as that of petrol, but it could be competitive with other liquid fuels produced from coal. In some countries where natural gas or waste vegetation are sources of methane, the liquid could be produced at quite a low cost.

The work at the Imperial College included the design and construction of a pilot methane liquefier and a liquid methane rectifying-column, the design of vacuum-jacketed vehicle tanks and of equipment for feeding the liquid to the engine, and tests on engine performance and wear. In addition, numerous laboratory investigations were carried out on the vapour-liquid phase equilibria of mixtures containing methane; the heat transfer coefficients of methane and other gases under forced convection at low temperatures; the measurement of thermal con. ductivities of insulating materials at low temperatures; the measurement of heat radiation from various metal surfaces from the point of view of their incorporation in vacuum-jacketed vessels; the solubilities in water of methane, carbon dioxide, and their mixtures under pressure, and the fire-hazards attendant upon the use of liquid methane on vehicles.

With the end of the War and the end of restrictions on the Department's activities, the scope of the work was extended. A laboratory liquid-air plant utilizing Freon-12 as a pre-cooling fluid has been designed and is now being constructed. A method of purifying gases from small quantities of condensable constituents by the injection of a stream of cold pure gas is being tried out, and experiments are in progress to determine the factors influencing the adhesion of frozen particles to tube walls. Both these investigations derive from the general problem of the purification of industrial gases prior to liquefaction. An apparatus has been constructed for the determination of the latent heat of vaporization of binary mixtures at low temperatures and pressures above atmospheric ; and an investigation is in progress on the properties of lubricants at low temperatures.

Calculations and experiments have been made on the extraction by refrigeration of olefines and methane from coal or coke-oven gases, the first being of use in chemical synthesis, the second in the form of liquid, as a thermal reservoir to meet peak loads on town-gas undertakings. The methane would be extracted and stored as liquid at periods of low demand, and re-gasified to enrich water gas at periods of high demand.

The experimental work of the Department was exhibited to the Low Temperature Group, and the various activities were discussed in greater detail in the course of short addresses given by Sir Alfred Egerton, Prof. D. M. Newitt, Mr. M. Pearce and Dr. T. A. Hall, on the storage of liquefied gases, on the unexplored regions of the temperature-entropy diagram, and on the purification and separation of constituents of coal and coke-oven gas by liquefaction.

\section{IMPORTANCE OF TAXONOMY}

TN the course of his final presidential address to 1 the Linneay Society on May 24, Mr. A. D. Cotton took decasion to emphasize the importance of taxonomy and the need of securing additional workers in this branch of biology.

Spesking of the distribution of the Dendrosenecios on the equatorial mountains of Africa, he said it wos the impossibility of reconciling the records of the species on Kilimanjaro and on other mountains which led him to take up the study of the group. Many records existed in systematic literature; and ecologists and others used these records for their field work and in their published papers. When he came to study them he was confronted by a state of affairs only too familiar to all experienced taxonomists. Except where new species are concerned; no record, whether in floristic or ecological literature, could be accepted at its face value. This casts no reflexion on the botanists of the past. The fact illustrates the slow growth and evolution of a difficult branch of botanical science and demonstrates the imperative need for further taxonomic research and of a more intensive type.

Mr. Cotton does not maintain that the classification he has prepared is perfect or final, because much more field work is necessary; but with the aid of as much co-operation as possible in the field and by examination of all herbarium material extant, it is believed to be reasonably correct.

The Linnean Society is the one Society which, from its inception to this day, has cared for general taxonomy, and at the present time, when the subject tends to be overshadowed by other branches of biology, the Linnean Society has never shrunk from bearing the very heavy expense of publication of systematic papers even to the serious depletion of its funds. Systematic papers are not usually suitable for reading at meetings but are prepared for use and for reference. They have a permanent value not often attained by other papers. The Society aims at being broad in its interests, but one of its principal functions is the publication of such papers for the benefit of botanists and zoologists throughout the world. Taxonomic work and its publication is, in fact, in large measure, essentially a service. 